\title{
Revealing the Translation of Slang Words in 'Prison Break's Movie Subtitling from English into Indonesian
}

\author{
Faisal Reza ${ }^{a, *}$, Widyastuti ${ }^{b}$ \\ ${ }^{a, b}$ English Literature, Faculty of Languages and Arts, Universitas Negeri Surabaya \\ *Corresponding author: faisal.17020154080@mhs.unesa.ac.id
}

\begin{abstract}
Translating slang words is a challenge because many countries, even populations in the same country, that have different words of slang and different definitions. This forces a translator to consider the background of the content and meaning of the situation of the source text to render the precise translated slang words. This study aims to examine the quality of translated slang words that are used in jail in the film "Prison Break". In this context, prison slang is defined as an argot that used primarily by criminals in jail. To reveal Baker's translation strategies that are chosen in translating prison slangs, content analysis was chosen as data collection technique. Prison Slang words that were used by the main character inside prison grouped based on slang classification proposed by Allan $\&$ Burridge (2006). Then matching the source text and target text was conducted to recognize the translation procedures that were applied by the subtitlers using Baker's translation strategies (2018). The result showed three strategies applied to translate prison slangs, namely similar meaning and form, similar meaning but dissimilar form, and paraphrase. These result suggest that particular strategy is chosen for given slang words. Similar meaning and form is selected for fresh and creative and imitative. Similarly paraphrase is chosen for flippant and fresh and creative. the third is similar meaning and dissimilar form is employed for all types.
\end{abstract}

Keywords: Subtitling, Prison Slang words, Translation Strategies.

\section{INTRODUCTION}

Currently, film is rising strong in Indonesia in particular. There is a curious in watching English films. This is why a subtitle is generally offered in the film to help viewers identify and appreciate the films. Nevertheless, the sense of the subtitle which may be triggered by the incorrect understanding or inappropriate form of translation is hard for them to grasp. The interpreter definitely has a lot of trouble to contend with in interpreting. They may not only translate a word or phrase, but they need to grasp entirely the meaning of terms in the source language to fit the naturalness of the target language. The slang terms are in the film and subtitlers would translate them for the written subtitles. This is a challenge because there are countries, including populations in the same country, that have different words of slang and different definitions. To translate slang words properly, the translator has to look at the background of the content and meaning of the situation. The movie includes visuals, rhythm (movement), the blend of casual images, oral and written speech, and artificial or natural sounds, not as plain as can be seen. Slang 
is the usage of very casual words and phrases that are not known as normal language use. It is also used to say inappropriate or, to a lesser extent, taboo phrases. Nevertheless, Amari (2010) argued that Slang is compatible in its classification, which is: more lexical, rather than phonologically or syntactically, and not grammatically, because slang items never breach the semanthropic consistency of a phrase and experience the same morphologic processes as the remainder of the language, such as meaning. Slang is used to add humor and fun to one's speech. Amari (2010) also stated that slang is simply an entity that can express interest and newness or context knowledge regarding the user's social status, but does not inherently influence its communication role. In other words, if it is to be used in the linguistic definition in general, slang suits rather than repeating as a foreign optional feature. The truth is that language is a social phenomenon by its very nature; in particular, the language that people use in their daily lives is more fluid, diverse and distinct from its literary equivalent. It is claimed that some language forms and components are socially dependent and are commonly understood as such. Slang is no exception to these trends and evaluations. Slang is a social phenomenon which serves the language's social nature. In addition, Allan \& Burridge (2006) classify slangs into five categories. They are fresh and creative, flippant, imitative, acronym, and clipping.

For further explanation for slang classification, Allan \& Burridge (2006) define types of slang words as follows: the first is fresh and creative. It is the slang of multiple words in an informal environment to describe something. Many words in our subconscious that are already familiar could be dialect words we do not recognize. Furthermore, it suggests that it is common to mind why these slang terms used to appear years ago. For instance is the word "mom" referring to an elderly lady. Secondly is Flippant which has no actual meaning in its own words. The example is the phrase "break a leg," which means as "good luck". It is a cinematic superstition that has the hope of being an enticing destiny with good luck. The third is imitative in which the slang term coming from a Standard English word, i.e. to be used in a particular manner by standard English terms or to combine two separate words. The word "wanna" is an example of slang derived from the phrase 'want to'. An Acronym is rendered by a word formed in a sentence, or by initials from a set of words or syllables, by the first letters of a word and pronounced as a new word. An example is "asap" with "as soon as possible" acronym. The last one is clipping. It means that by deleting a certain component of the long term, a slang word is rendered with the same sense to become a shorter version. This example is the word "till," which comes from "untill". Slang language is a key issue for the interpreter for subtitles in the film. They must understand both the slang language (SL) and the target language (TL). Furthermore, the translator must pick, compare, and balance the best words in both languages to translate the SL without changing context. That means they must find each word's definition and equivalence. Baker (2018) proposes translation strategies toward idioms into four types: similar meaning and form, similar meaning but dissimilar form, paraphrase, and omission. Using a language with the same meaning and form, converting a phrase from the source language to the target language in the same language but with specific lexical elements, to match cannot be identified in the target language or where, in consideration of the variations between the stylistic tastes of the source and target languages, requiring the full elimination of the language in the broad file in respectively. This study focused to examine the strategy to translate slang in subtitling "Prison Break" movie from English into Indonesian based on kind of slang 
words that used by the characters in the movie. Relating to the function of prison slangs, Schulte (2010) emphasizes that the prison slang is continually renovating to preserve the vigor it requires to function. Prison slang tend to have lower stability than regular lexical elements where there is different words that usually use inside the prison and sometimes makes a misunderstanding for most people since the argot is mainly used in penal institutions for inmates and prisoners. It's an anti-linguistic sort. Many of these terms apply to unlawful activity, detention, court proceedings, street life and various categories of prisoners. Based on the explanation before, the problem of the study focused what translation strategy that used to render prison slangs that were used by criminals in prison institution. This is a challenging point in translation of slang in a movie since there is a different culture in speaking particularly in a prisoner's daily conversation. Prisoners obviously also do not want to be heard what they think and to preserve a sort of counterculture, it may be partially responsible for the transience of prison argot or prison slang that jails are changing population, but the impact of population changes on linguistic use need to be confirmed. Moreover, to a certain degree, the prison slang needs to be ingenious and much of its lexicon short-lived, precisely because two of its principal roles are to maintain an anti-society 2 type or counter-reality (Ciechanowska \& Kleparski, 2016)

There are several previous studies that share the same interest. The first previous study is the article written by Kusumastuti and Hariyanti (2019) with the topic is subtitle analysis of idiomatic expressions. This article actually has the same scope as this study, which applied the same the translation strategy that proposed by Baker (2018). However this study added idiomatic expressions in the subtitles in the movie. This study resulted in translation of similar meaning and form, similar meaning but dissimilar form and translation by paraphrase are the most common localization technique used in language translation. The second previous study is the article written by Wicaksono \& Wahyuni (2018). This article also discussed the translation in idiomatic translation. However, the main problem is the terms of the analysis. This paper examined the idioms in Indonesian legends that were translated into English. This study uses the term "movie" as a term, and the translation is from English (source language) into Indonesian (target language), whereas the previous study is the opposite. This research has shown that paraphrasing language speech translation technique is one of the most influential idiom translation techniques used by the translator in five Indonesian Legends (eleven out of 18 cases). In the meantime, omission was the second most frequent tactic (six out of 18 cases). Last but not least, was the technique of similar meaning and form, one of eighteen examples. It showed that only three strategies from the five main strategies proposed by Baker (2018) for the translation of idiomatic expressions which were applied. Moreover, the article has the same strategy for translating the idiomatic expressions as the previous study and this research. The last previous study is an article that was written by Khoshniyat \& Dowlatabadi (2014). This article studied using Kövecses' (2006) idioms theory and Lakoff \& Johnson's (1980) the philosophy of metaphorical words. The result of this research actually showed that collaboration with conceptual metaphors and films can be beneficial to young Iranian students in a 'from theory to reality' movement. This was an enjoyable, suitable and less challenging technique for children.

The present study investigated the translation strategies that were chosen by the translator to render prison slangs used by characters in Prison Break's movie from English 
into Indonesian. the film by contrasting its spoken conversations, which were written in the form of a film script. The subtitle relates to the goal. The spoken words or the film script, however, apply to the original language. In this study, the writer uses several theories. They are Allan \& Burridge slang classification (2006) for classifying the kind of slang that is used and Baker's strategies of subtitling (2018) for analyzing the translation strategy for translating the slang words.

\section{RESEARCH METHOD}

To reveal the types of translation strategies of prison slangs, the qualitative design is chosen to depict the phenomenon prison slangs descriptively. A qualitative approach is required if a written language is to be analyzed and explored, and it will help people derive meaning from social phenomena (Merrriam, 2009). Since slang occurred spread and spread over time. The object of the study were the subtitles of Prison Break's movie that contained slang words were used by characters inside the jail. There are 8 characters to be taken, i.e. Michael Scofield, Lincoln Burrows, Fernando Sucre, Sara Tancredi, David "Tweener" Apolskis, John Abruzzi, Brad Bellick, Franklin "C-Note", and Theodore "T-Bag" Bagwell. The instrument of the study was the documentation of tape scripts of the subtitle of a Prison Break's movie and focused on the slang words that used in the movie. The data were collected based on the types of English idioms in the source texts then matched the translated slang words to recognize the translation strategies which were chosen by the translator. Then, this strategies can predict the quality of the translated product. To gather the data for this study, several steps were followed: watching the Prison Break's movie several times, collecting the slang words that uttered by the characters in the movie, then classifying and analyzing the data based on the types of slang. After determining the type of slang, the strategies used for translating it through subtitling were examined and compared between ST and TT.

\section{FINDINGS AND DISCUSSION}

It may be partly responsible for the transience of prison argot or prison slang because of the changing demographics of prison cultures, although the impact of demographic changes on language use needs to be seen. In addition, prison slang must in some way be ingenious and in a large part short-length, specifically when two of its principal tasks are the preservation and exclusivity of a kind of anti-society 2 or counterreality. Prisoners also seem to want to prevent prison officials from understanding their speech and maintain a kind of counter-culture. There were 22 prison slang words found in the film "Prison Break," and they were translated using three different strategies. Here the data would be classified based on the kind of slang that was found and what strategy were used to translate it. Table 1.1 is the relationship between slang types and the translation strategies that were found in Prison Break's movie. 
Journal of Literature, Linguistics, and Language Teaching

Volume 2 (1) 2021

ISSN: 2746-8968 (online)

https://journal.unesa.ac.id/index.php/nld/index

Table 1.1 the Relationship between slang types and translation strategies in

Prison Break's movie

\begin{tabular}{|c|c|c|c|}
\hline \multicolumn{2}{|l|}{ Slang } & \multicolumn{2}{|l|}{ Strategy } \\
\hline \multirow{2}{*}{ Flippant } & \multirow[t]{2}{*}{14} & Similar meaning but dissimilar form & 8 \\
\hline & & Paraphrase & 6 \\
\hline \multirow{3}{*}{ Fresh and Creative } & \multirow[t]{3}{*}{6} & Similar meaning and form & 3 \\
\hline & & Similar meaning but dissimilar form & 2 \\
\hline & & Paraphrase & 1 \\
\hline \multirow{2}{*}{ Imitative } & \multirow[t]{2}{*}{2} & Similar meaning and form & 1 \\
\hline & & Similar meaning but dissimilar form & 1 \\
\hline
\end{tabular}

Allan \& Burridge and translation methods suggested by Mona Baker shall be discussed in this chapter in the format of phrases containing idiomatic expressions in the subtitles of the film. The FreeDictionary.com, KBBI (Kamus Besar Bahasa Indonesia) and meanings of metaphor theory by Lazar (2003) are used to discover the meaning of idioms with a simple understanding of a word or sentence. Allan \& Burridge (2006) state that Slang is a language of a highly colloquial and contemporary type, considered stylistically inferior to standard formal, and even polite informal speech. It often uses metaphor and/or ellipsis, and often manifests verbal play in which current language is employed in some special sense and denotation; otherwise the vocabulary, and sometimes the grammar, is novel or only recently coined. Furthermore, Pollock (2006) advocates that Prison Slang is an object which is complex, ever changing. Any of the oldest representations may have very different significance today if seen at all. Terms tend to evolve over time and vary between organizations and around the world

The data above that shown in Table 1.1 indicate the strategies which are chosen by translator considering the types of slang words. Strategies similar meaning and dissimilar form and paraphrase are applied for flippant. This translated prison slang words are using this strategies because it converts a phrase from the source language to the target language in the same language but with specific lexical elements, for example is Datum 01:

\section{Datum 01}

ST: I've got news for you Michael. 'Trust me' mean absolutely nothing inside these walls.

TT: Aku punya kabar untukmu Michael. 'Percayalah' sama sekali tidak berarti apa-apa di dalam penjara ini. (04)

"These walls" refers to the prison itself. The word "walls" is chosen since the prison is surrounded by a wall and there is no way out. The character in the movie named CNote said it when he had a conversation with Michael Scofield in the yard inside the prison and this terms shows his irritation with the conditions inside the prison. These terms are translated into penjara using a similar meaning but dissimilar form strategy, with "these walls" representing the prison itself because there are only walls as far as the eye can see.

Other data also showed the prisoner's feelings about the prison as in datum 02

Datum 02

ST: Darwin wins inside these fucking hell. Not Einstein, Darwin.

TT: Darwin menang dalam penjara ini. Bukan Einstein, tapi Darwin (10) 
The character named T-Bag said it when he had a conversation after he had an issue with another character named Tweener. The phrase 'fucking hell' was chosen because the prisoner feels that he was living like in hell and he added "fucking" words to emphasize to express his frustration. This data is also translated using a similar meaning but dissimilar form strategy, with the term "fucking hell" describing a prison and the conditions that exist within it as if we were living in hell and supplemented with swearing words to demonstrate his emotional sense.

Another strategy is a paraphrase, is used by translators to translate flippant slang because this technique is particularly effective in the translation of slang, idioms, or other metaphorical words where a match cannot be identified in the target language or where, due to stylistic differences between the source and target languages as in datum 03

Datum 03

ST: Why don't you just doing a chin check?

TT: Kenapa kamu tidak berkelahi saja? (15)

This phrase was translated using paraphrase strategy because "chin check" has no significance meaning, but this term is chosen to symbolize a fight since most people will attack the chin during a fight to knock their opponent down or just to get off of his balance. This conversation occurred when the character named John Abruzzi was eating, then there was a commotion between the inmates. These terms were chosen because lots of cops were on guard during lunch time and he didn't want any of the guards to know about what happened.

\section{4}

Another flippant slang that is translated using the paraphrase strategy is in datum

ST: Don't ever doing the dutch, no matter what!

TT: Jangan pernah mencoba bunuh diri, apapun yang terjadi! (22)

This conversation occurs when an inmate was no longer strong enough to feel injustice in the prison and sought an advice from other inmates. Slang expression 'doing the dutch' which means committing suicide was translated as 'bunuh diri' in Indonesian. This translated slang words using a paraphrase strategy was applied because there is no actual meaning from the source text if this source words was translated literally into the target text.

Similarly, fresh and creative, that is the slang words having multiple words in an informal environment to describe something, has three possible translation strategies, namely similar meaning and form, similar meaning but dissimilar form, and paraphrase. The explanation of this kind of slang and translation strategy can be seen in the following data:

Datum 05

ST: what the hell is going on here?

TT: Apa yang terjadi? (18)

the phrase "what the hell" in the expression of "what the hell is going on here?". This dialogue occurs when the main character was almost apprehended by cops while attempting to escape through the wall in his room, and the cops suddenly said that to express his curiosity and anger because of the noise of punching holes in the wall and questioning what was really going on in his room. This data is translated using similar meaning and form. "What the hell" is an exclamation used to emphasize surprise, shock, anger, disgust, etc. In this phrase, "the hell" is used as an intensifier. It is not considered 
as the standard use of language in asking a question. The data is successfully translated from ST into TT using this strategy because there are the same lexical items, meaning, and form.

Another strategy to render fresh and creative expression was the similar meaning but dissimilar form. The example is in the datum 06 .

Datum 06

ST: Holy Shit! What you've done Sucre?

TT: Astaga! Apa yang telah kau perbuat sucre? (20)

The character in the movie named Michael Scofield, who was the main character, said "Holy Shit" when he was surprised by what his friend had done, named Fernando Sucre, which he felt would ruin all his escape plans. This data was translated using a similar meaning but dissimilar form strategy since it has the same meaning as ST and TT, which is to show surprise feelings but there is a different lexical item between ST and TT. "Holy shit", It is a kind of cursing/swearing. It is similar in meaning to "What a mess". Literally, "holy" means blessed, belonging to god and "shit" is very vulgar for human excrements. It's an expression of terror, awe, surprise, astonishment, etc., often at something seen for the first time or remembered immediately before using this term. While the translated slang words is 'astaga'. It is an exclamation word. This depicts the similar meaning but the source words is a phrase becomes a noun.

The third strategy for translating fresh and creative is a paraphrase. The example is in datum 07.

Datum 07

\section{ST: I'm not gonna blow it}

TT: Aku tidak akan mengacaukannya (01)

The phrase "blow it" means to ruin, mishandle, or fail to capitalize on an opportunity. The translated text becomes 'mengacaukan'. This translated slang using paraphrase strategy since a match cannot be identified in the target language or where, in consideration of the variations between the stylistic tastes of the source and target texts. This dialogue took place when there was one inmate who wanted to join a team to escape from the prison., but another team member doubted him and feels he wouldn't be of any use to join this team.

The final slang category is imitative, which is derived from a standard English word: to be used in a specific manner by standard English terms or to combine two separate words. Translation strategies which were chosen by the translator are similar meaning and form, and similar meaning but dissimilar form. The illustration of these strategies are as in datum 08 and datum 09.

Datum 08

ST: Listen Michael, i wanna tell you something

TT: Dengar Michael, aku ingin memberi tahu sesuatu (17)

The first strategy is similar meaning and form is depicted in datum 08. As previously stated, wan na is a combination of two separate words that means 'want to or want a'. The character in the movie said it when he wanted to or will do something and which actually has the same meaning as wanting to. This strategy was applied because lexical item between 'wanna' in English and 'ingin' in Indonesian are same in meaning and form..

Another strategy for translating imitative is similar meaning but dissimilar form. The example is in datum 09. 


\section{Datum 09}

ST: Are you okay Sara?, lemme check the condition outside

TT: Apakah kamu baik baik saja Sara?, aku akan mengecek kondisi di luar sana (19) Slang word "Lemme" is a combination of the two words "let me" that separate them.The character named Michael Scofield in the movie said it to his girlfriend Sara Tancredi, who aimed to let him do the thing or volunteer to do something which has the same meaning as "let me" is 'ingin' in Indonesian. This slang word is translated using a similar meaning but dissimilar form strategy, which was chosen because these words have similar meanings in ST and TT but different lexical items in ST and TT.

Broadly speaking, Dziedzic-Rawska (2018) emphasizes that prison slang is a culturally defined and supervised prison composed of a series of values that control behaviors, relationships with prisoners and correctional personnel. The development of slang in prison has largely been the product of prison and correctional experiences. Prisons are absolute structures that are intended to isolate individuals physically and symbolized from society in general and at the same time govern any part of life. Conditions of confinement lead to environmental and psychological impaired conditions, which in turn cause "pain" due to the absence of rights, mobility, control, materials, products, safety, heterosexual relations and freedoms. The slang of prison includes beliefs, behaviors, rules and conduct. A collection of principles that encourages people to "make time," "mind your own business," "be tough" and "never be too polite with a correctional officer" are central to this community. Adherence to these principles enables prisoners to promote unity within the community, oppose it, gain power and status and reduce the pains of imprisonment while also offering guidance for proper conduct and interactions. This study differs from the previous study, as stated in the introduction. The first study conducted by Kusumastuti and Hariyanti (2019). This study classifies the linguistic form that is not explained in this research since the topic itself only focused on the prison slang translation. The second previous study is an article written by Wicaksono and Wahyuni (2018) whose topic is translation of idiomatic expressions in an Indonesian legend's story, which is in contrast to this study because the translation is from English into Indonesian, whereas the previous study is the opposite. The final study is an article written by Khoshniyat and Dowlatabadi (2014), which has a different topic than this study but is still being discussed, which is idioms. This article stated that idioms are taught late at institutes or are entirely excluded from schools and this article provided the relevance of idioms in all languages and the complexity of studying these expressions. One may also be tempted not to miss the golden chance to teach children languages.

\section{CONCLUSION}

It is not straightforward to translate the slang from the source to the target language. This is because slang is a kind of figurative language, it has a specific meaning rather than its literal meaning. In order to translate the idioms, the translator has to adopt those techniques to effectively translate the intent of the SL languages into the TL text. In general, this study found that the translator successfully translated English idioms into Indonesian. This study found 22 prison slang words in the subtitling of the "Prison Break" film. They are 14 flippant, 6 fresh and creative and 2 imitative in respectively. The translator employed three strategies: four similar meanings and forms, twelve similar 
meanings but dissimilar forms, six paraphrases, and no omissions. Flippant is the dominant slang that was found in this study and translation strategy similar meanings but dissimilar form is favor in translating slang words.

Not only revealing the translation strategies that were used by the translator, but also the translation quality in terms of accuracy, readability, and naturalness so that the equivalences of the slang expression can be measured. Besides, to examine these strategies to other types of idioms such as proverbs, euphemisms, and cliché in order to design the guidance in translating idioms.

\section{REFERENCES}

Allan, K., \& Burridge, K. (2006). Forbidden words: Taboo and the censoring of language. In Forbidden Words: Taboo and the Censoring of Language. https://doi.org/10.1017/9780511617881

Baker, M. (2018). In other words: A course book on translation. Abingdon: Routledge.

Ciechanowska, A., \& Kleparski, G. A. (2016). On the semantic features of prison slang. Dziedzic-Rawska, A. (2018). Principle of pithiness in US prison slang. Lublin Studies in Modern Languages and Literature, 41(2), 12. https:// doi.org/ 10.17951/ lsmll. 2017. 41.2.12

Amari, J. (2010). Slang lexicography and the problem of defining slang. ORA Journal, $1-11$.

Khoshniyat, A. S., \& Dowlatabadi, H. R. (2014). Using Conceptual Metaphors Manifested in Disney Movies to Teach English Idiomatic Expressions to Young Iranian EFL Learners. Procedia - Social and Behavioral Sciences, 98, 999-1008. https://doi.org/10.1016/j.sbspro.2014.03.5.10

Kövecses, Z. (2006). Language, Mind, and Culture. New York: Oxford University Press.

Kusumastuti, A. \& Haryanti, D. (2019) Subtitle Analysis of The Idiomatic Expressions Used in The Subtitles of That Thing You Do! Movie. Skripsi thesis, Universitas Muhammadiyah Surakarta

Lakoff, G., \& Johnson, M. 1980. The metaphorical structure of the human conceptual system. Cognitive Science, 4(2), 195-20.

Lazar, G. (2003). Meanings and metaphors: Activities to practice figurative language. Book.

Merrriam. B, S. (2009). Qualitative Research: A Guide to Design and Implementation. Retrieved from http://library1.nida.ac.th/termpaper6/sd/2554/19755.pdf

Pollock, J.E. (2006). Prison Today and Tomorrow. Sudbury: Jones and Burtlet.

Schulte, M. (2010). "The language of the underworld and its sociolinguistic significance", Contributions to the Study of Language, Literature and Culture. Arbeitsblätter des Anglistischen Seminars Heidelberg, 1, 45-60.

Wicaksono, D. B., \& Wahyuni, E. (2018). an Analysis of the Strategies Used in Translating Idioms in Indonesia Into English Found in Indonesian Legends. $A$ Journal of Culture English Language Teaching Literature \& Linguistics, 3(1), 45. https://doi.org/10.22219/celticumm.vol3.nol.45-55 